\title{
Potencial antimicrobiano de Allium sativum L.: uma revisão
}

\author{
Allium sativum L. Antimicrobial potential: a review \\ Allium sativum L. potencial antimicrobiano: una revisión
}

Recebido: 12/10/2021 | Revisado: 20/10/2021 | Aceito: 25/10/2021 | Publicado: 27/10/2021

\author{
Alexandre Santos Leite \\ ORCID: https://orcid.org/0000-0003-1576-3951 \\ Faculdade Integrada Carajás, Brasil \\ E-mail: xande1848@gmail.com \\ Jânio Sousa Santos \\ ORCID: https://orcid.org/0000-0003-2180-1109 \\ Faculdade Integrada Carajás, Brasil \\ E-mail: santosjs.food@gmail.com
}

\begin{abstract}
Resumo
O Brasil tem uma longa história de uso de plantas medicinais no tratamento de problemas de saúde da população, uso baseado na experiência e disseminado pela oralidade e vivência, sendo amplamente utilizado até meados do século XX. O Allium sativum L. é um dos medicamentos mais antigos do mundo. Por suas diversas atividades biológicas. No Allium sativum L. e encontrado a alicina resultante da ação da enzima alinase junto a aliina após esmagamento do bulbo do alho, Além de alicina, o extrato de alho possui como metabolitos secundários, alcalóides, saponinas, taninos, terpenos e flavonoides, os quais podem estar suscetíveis à atividade antimicrobiana. Uma revisão integrativa de literatura foi realizada, com buscas de documentos científicos individualizados nas bases de dados bem como: Scielo, Medline (PubMed), Lilacs, Scopus, ScienceDirect, Periódicos Capes e em repositórios científicos, foi como critério de inclusão de documentos de cunho cientifico, nos idiomas português, inglês e espanhol, que apresentou relação do potencial antimicrobiano de Allium sativum L. Diante disso, a pesquisa teve como objetivo mostrar os principais metabólitos provenientes do Allium sativum L. e verificar sua resposta e relatar a concordância de diferentes estudos em relação ao potencial do Allium sativum L., as propriedades antimicrobianas e fúngicas frente a bactérias gram positiva e gram negativas e fungos, envolvendo levantamento bibliográfico.
\end{abstract}

Palavras-chave: Allium sativum L; Potencial antimicrobiano; Fitoquímicos.

\begin{abstract}
Brazil has a long history of using medicinal plants in the treatment of health problems in the population, a use based on experience and disseminated by orality and experience, being widely used until the mid-twentieth century. Allium sativum $\mathrm{L}$. is one of the oldest medicines in the world. For its diverse biological activities. In Allium sativum L. allicin resulting from the action of the enzyme allinase together with allin after crushing the garlic bulb is found. In addition to allicin, the garlic extract has as secondary metabolites, alkaloids, saponins, tannins, terpenes and flavonoids, which may be susceptible to antimicrobial activity. An integrative literature review was carried out, with searches of individual scientific documents in the databases as well as: Scielo, Medline (PubMed), Lilacs, Scopus, ScienceDirect, Capes Periodicals and in scientific repositories, as a criterion for inclusion of documents of a nature scientific, in Portuguese, English and Spanish, which presented a relation of the antimicrobial potential of Allium sativum L. Therefore, the research aimed to show the main metabolites from Allium sativum $\mathrm{L}$. and to verify their response and report the agreement of different studies in relation to the potential of Allium sativum L., the antimicrobial and fungal properties against gram positive and gram-negative bacteria and fungi, involving a literature review.
\end{abstract}

Keywords: Allium sativum L; Antimicrobial potential; Phytochemicals.

\section{Resumen}

Brasil tiene una larga historia de uso de plantas medicinales en el tratamiento de problemas de salud en la población, uso basado en la experiencia y difundido por la oralidad y la experiencia, siendo ampliamente utilizado hasta mediados del siglo XX. Allium sativum L. es uno de los medicamentos más antiguos del mundo. Por sus diversas actividades biológicas. En Allium sativum L. se encuentra la alicina resultante de la acción de la enzima alinasa junto con la alina después de triturar el bulbo de ajo. Además de la alicina, el extracto de ajo tiene como metabolitos secundarios, alcaloides, saponinas, taninos, terpenos y flavonoides, que pueden ser susceptible a la actividad antimicrobiana. Se realizó una revisión integradora de la literatura, con búsquedas de documentos científicos individuales en las bases de datos así como: Scielo, Medline (PubMed), Lilacs, Scopus, ScienceDirect, Capes Periodicals y en repositorios científicos, como criterio para la inclusión de documentos de un Nature Scientific, en portugués, inglés y español, que presentó una relación del potencial antimicrobiano de Allium sativum L. Por lo tanto, la investigación tuvo como objetivo mostrar los principales metabolitos de Allium sativum L. y verificar su respuesta y 
reportar la concordancia de diferentes estudios. en relación al potencial de Allium sativum L., las propiedades antimicrobianas y fúngicas frente a bacterias y hongos gram positivos y gram negativos, involucrando una revisión de la literatura.

Palabras clave: Allium sativum L; Potencial antimicrobiano; Fitoquímicos.

\section{Introdução}

Os fungos são amplamente distribuídos na natureza e há vários fatores que facilitam sua disseminação, incluindo vento, água, comida e animais. Embora muitos fungos façam parte da microbiota normal apenas alguns são considerados microrganismos patogênicos, quando esses microrganismos encontram fatores locais ou sistêmicos suscetíveis, eles podem invadir tecidos e se tornar bactérias patogênicas (Pigatto, Lovison, \& Cattani, 2019).

Existem as chamadas infecções oportunistas, as quais os patógenos causam doenças leves ou nenhuma doença em indivíduos saudáveis, mas podem infectar e causar doenças graves em indivíduos imunossuprimidos. Infecções simples, como candidíase, podendo se tornar grave e colonizar o esôfago, estômago e intestinos de pacientes com síndrome da imunodeficiência adquirida. Portanto, na presença de infecção por fungos, é importante novas tecnologias que possam ser aplicadas de forma eficaz para evitar possíveis agravos à saúde dos pacientes (Burian, Sacramento \& Carlos, 2017).

Quando as cepas microbianas se multiplicar mesmo na presença de concentrações relativamente altas de antimicrobianos, a resistência bacteriana aparecer, o que torna difícil o tratamento de infecções bacterianas com os medicamentos existentes (Basso, Pulcinelli, Aquino, \& Santos, 2016).

O Staphylococcus aureus é uma das espécies bacterianas mais comuns e a mais tóxica de seu gênero. A transmissão endógena desta bactéria é a mais comum e é a causa de muitas infecções adquiridas em hospitais. Isso é causado pela presença de Staphylococcus na pele e nasofaringe de 15\% das pessoas saudáveis (Lima, Borges, Parente, Victória \& Oliveira 2015).

$\mathrm{O}$ aumento da prevalência de cepas bacterianas multirresistentes e o recente surgimento de cepas com sensibilidade reduzida a antibióticos têm despertado a atenção para os casos de infecções bacterianas refratárias, e requerido a busca urgente de agentes antimicrobianos de produtos naturais (Lawal, Oibiokpa, Mohammed, Umar \& Haruna, 2016). Comparados com os produtos sintéticos considerados inseguros para os serem humanos por causarem vários efeitos colaterais e ao meio ambiente e preços onerosos, surgem os produtos fitoterápicos que hoje simbolizam segurança (Kifayatullah, Senguptha, Mustafa, Das, \& Sisugoswomi, 2015), o aumento pelo uso de medicamentos fitoterápicos deve-se aos benefícios causados no organismo e por serem inexistentes de efeitos colaterais e ainda sendo de baixo custo e fácil preparo. (Lozano, Bagne, Hora, 2015).

O homem em buscava da cura para doenças, passou a utilizar produtos vegetais infundindo como tratamento e como condimentos. Por meio desse uso informal de plantas, as primeiras grandes descobertas tornaram-se hoje o centro da química e da pesquisa medicinal moderna (Cunha, Moura, Barbosa \& Santos 2016).

O Brasil tem uma longa história de uso de plantas medicinais no tratamento de problemas de saúde da população. Há alguns anos vem sendo estudadas especiarias e conhecimento empírico sobre plantas que são utilizadas para fins terapêuticos. O A. sativum L. e um exemplo, uma especiaria amplamente utilizada pelo mundo, é bastante utilizado para fins terapêuticos (Oliveira, Cavalcante, \& Ribeiro, 2021).

O metabolismo secundário da planta, substâncias formadas por meio do metabolismo primário, formam vários compostos orgânicos, que podem produzir atividades biológicas. As principais categorias de metabólitos secundários identificados nas plantas são os compostos que contem nitrogênio, compostos fenólicos e terpenos. No Allium sativum L. além da alicina, nos extratos do alho também possui metabolitos secundários bem como alcalóides, saponinas, taninos, terpenos e flavonoides, os quais podem estar suscetíveis à atividade antimicrobiana e fúngica (Felix, Medeiros \& Medeiros, 2018). 
Desta forma essa revisão tem como objetivo principal compreender os efeitos químicos das substâncias presentes no Allium sativum L. e relatar a concordância de diferentes estudos em relação ao potencial do Allium sativum L., as propriedades antimicrobianas e fúngicas frente a bactérias gram positiva e gram negativas e fungos, envolvendo levantamento bibliográfico.

\section{Metodologia}

Uma revisão integrativa de literatura foi realizada, com buscas de documentos científicos individualizados nas bases de dados bem como: Scielo, Medline (PubMed), Lilacs, Scopus, ScienceDirect, Periódicos Capes e em repositórios científicos. Adotou-se como critério de inclusão documentos de cunho cientifico, nos idiomas português, inglês e espanhol, que apresentou relação do potencial antimicrobiano de Allium sativum L. em um recorte temporal entre 2011 a 2021, como intuito de ponderar as evidências científicas dos últimos dez anos. Foram excluídos os documentos que não apresentaram relação com os objetivos da pesquisa, por meio da leitura de título e resumo. Foram utilizadas as seguintes palavras-chave para busca dos trabalhos científicos: "Allium sativum L.”, "propriedades do Allium Sativum L.”, "propriedades químicas do Allium sativum L.", "atividades do Allium sativum L. sob Staphylococcus aureus e cândida albicans", "Allium sativum L. e fitoterapia", "fitoquímicos", "Staphylococcus aureus", ” cândida albicans" (Lima, Alexandre \& Santos 2021).

\section{Resultados e Discussão}

Fitoterápicos

A fitoterapia e tão antigas quanto a história humana. Sua primeira citação é encontrada na literatura, onde Diocles, um dos discípulos de Aristóteles, descreveu os efeitos fisiológicos das plantas medicinais em detalhes. Em países em desenvolvimento, a extração de medicamentos ainda é frequentemente feita em casa, não há controle de dose ou contraindicações de observação ou mesmo efeitos colaterais (Milani, Teixeira, Sousa, Abreu, \& Ninahuaman, 2016).

O Brasil é um país com uma grande biodiversidade, e as práticas integrativas e complementares no cuidado à saúde, como o uso de fitoterápicos e plantas medicinais, são reforços que utilizam dessa particularidade (Goés, da Silva \& de Castro, 2019). Segundo Brasil (2014), são considerados medicamentos fitoterápicos os obtidos com emprego exclusivo de matériasprimas ativas vegetais, cuja segurança e eficácia sejam baseadas em evidências clínicas e que sejam caracterizados pela constância de sua qualidade.

E importante uso racional de plantas medicinais sendo efetivadas na atenção primaria a saúde, mais de extrema importância a orientação sobre como utilizar um medicamento fitoterápico, de modo que consciente e seguro garantindo seu benefício e prevenindo risco (Goés, da Silva \& de Castro, 2019).

Com a segurança e eficácia das plantas medicinais comprovadas, aumentou a procura e o uso de plantas medicinais e fitoterápicos. O outro motivo da alta demanda é o elevado custo das drogas sintéticas, reações adversas, e resultados que nem sempre são satisfatórios, o que levam os pacientes a buscarem alternativas de tratamento menos agressivas (Figueredo, Gurgel, Gurgel, 2014).

Nos últimos anos, algumas especiarias foram pesquisadas e utilizadas para fins terapêuticos, sendo o alho, uma especiaria amplamente difundida no mundo todo, muito utilizado para tais fins. O Allium sativum L. foi muito utilizado como medicamento em textos médicos Codex Ebers de aproximadamente 1550 anos a.C, por povos egípcios (Silva, Silva, do Carmo, 2016). As indicações do Allium sativum L. foram descritas para tratamentos de patologias como, infecções circulatórias, inflamações de ferimentos, resfriados, picadas de insetos e em infestações parasitárias. (Oliveira, Cavalcante, \& Ribeiro, 2021).

A composição química do Allium sativum L. possui aliina que é convertida em alicina por uma reação da enzima alinase, após ser macerado ou cortado como na presentado na Figura 1. Allium sativum L. detém vitaminas do complexo B e 
minerais, como, ferro, magnésio, fósforo, potássio, sódio, zinco, cobre, manganês e selênio. Nesse contexto, e justificado a ampla utilização da espécie Allium sativum L. Como moduladora de uma variabilidade de efeitos biológicos (Silva, Silva, do Carmo, 2016).

Figura 1. Reação química entre Aliin enzima Alliinase produto final Alicina.
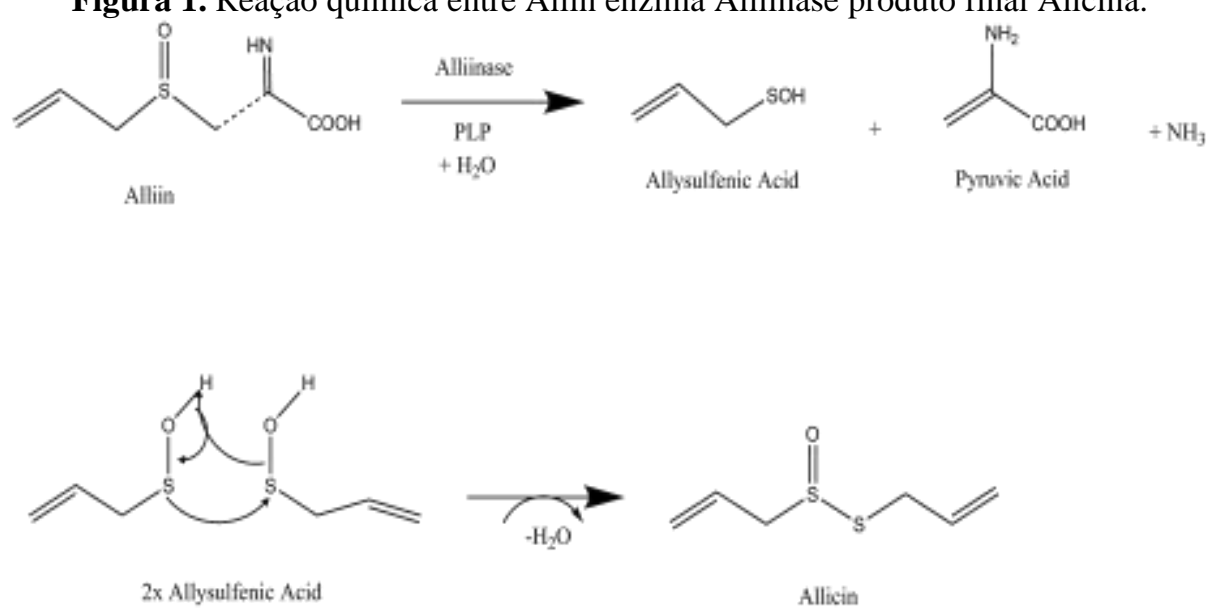

Fonte: https://www.pngegg.com/pt/png-ypgkz

Na literatura da ação antimicrobiana causada pela alicina, responsável pelo bloqueio das enzimas metabólicas sulfidrilas e por contato específico pelo grupo tiol, resultantes nos microrganismos (Felix, Medeiros, Medeiros, 2018). A classe pesquisadora procura a partir de estudos e pesquisas introduzir gradualmente esse fitoterápico em tratamentos alternativos pelos poucos efeitos secundários (Silva, Silva, \& do Carmo, 2016).

O Allium sativum L. que possui propriedades químicas importante na resposta contra microrganismos, retardando ou inibindo a multiplicação de bactéria (Cruz, 2015). Em análises bioquímicas do extrato aquoso do alho, e evidenciado substancias derivadas do enxofre, como a aliina, alicina e o ajoeno, substâncias influentes sob o metabolismo de microrganismos com propriedade antimicrobiana e fúngica (Almeida, Godoi, Santos, Lima, \& Oliveira, 2013).

\section{Infeç̧ões Fúngicas}

São reconhecidas cerca de 300 espécies fúngicas que são patogênicos, e existente cerca de 1,5 milhões de espécies fúngicas que não causem danos a hospedeiros, as das infeções fúngicas ocorre quando um hospedeiro e exposto a fontes de contaminação, assim os fungos invadem os tecidos do hospedeiro por uma ou mais espécies, sendo de forma superficial ou profunda, afetando tecidos e órgãos como pulmão e fígado, podendo-se disseminar através do sangue (Veríssimo, Sabino, Martins \& Brandão, 2016).

Alguns fungos são considerados oportunistas, infetando apenas hospedeiros com comprometimento do sistema imunitário, quando há no organismo um desequilíbrio parasita-hospedeiro, alguns há alguns fatores que são utilizados pelas leveduras para fazer a colonização do meio tais como: aderência, polimorfismo, variabilidade fenotípica, produção de enzimas extracelulares e toxinas (Oliveira, Cavalcante, \& Ribeiro, 2021). A aderência das leveduras as células epiteliais são por vários fatores, variam do tipo de complexos proteicos na superfície da célula do hospedeiro, formação do tubo germinativo, fatores como o pH do meio, temperatura, produção de enzimas extracelulares, disponibilidade de carboidratos, que podem favorecer a aderência do fungo na derme do hospedeiro (Santana, Ribeiro, Menezes, \& Naves, 2013).

Um importante fator de virulência é, as enzimas extracelulares produzidas por fungos, que destroem as paredes celulares e degradam as membranas da mucosa, que facilita a adesão da Candida albicans, e das infecções celulares. As 
toxinas que ela libera podem causar a morte de animais de laboratório e até mesmo produzir grandes quantidades de anticorpos. Essas estratégias de se estabelecerem no corpo de forma oportunista permitem a Candida, causar infecções, superando as defesas do hospedeiro (Oliveira, Cavalcante, \& Ribeiro, 2021).

A formação do micélio de Candida. Devido à variabilidade antigênica da superfície e do formato do micélio, a virulência é aumentada, o que facilita uma maior adesão e dificulta a realização de fagocitose extracelular e intracelular pelo sistema imunológico. Quando as células de levedura são engolfadas por macrófagos e neutrófilos, elas produzem hifas e secretam proteases relacionadas às hifas para matar esses fagócitos. Em comparação com os esporos, as hifas têm uma capacidade mais forte de aderir e penetrar nas células epiteliais humanas. Na forma micelial, a Candida albicans é invasiva e patogênica, enquanto na forma de levedura é simbiótica e não patogênica (Santana, Ribeiro, Menezes, \& Naves, 2013).

\section{Infecções Bacterianas}

$\mathrm{O}$ consumo de antimicrobianos indiscriminado contribui para o aumento da resistência bacteriana, as bactérias adquirem resistentes em contato com os antibióticos, logo como forma de sobrevivência as bactérias se adaptam, e sofrem mutações genéticas. Os pacientes que são submetidos a internação, hospitalização são avaliados como potencial de risco, expostos a adquirirem infecções por meio de procedimentos invasivos bem com introdução de cateteres, endoscopia e traqueostomia (Menezes, Porto, \& Pimenta 2016).

As bactérias gram negativas são formadas por uma membrana plasmática com duas camadas, uma interna, mais delgada, constituída por peptidoglicanos e a outra externa, de origem lipídica, contendo lipopolissacarídeo, já as bactérias gram positivas possuem parede celular com uma única e espessa camada de peptidoglicanos e com presença de ácido teicoico, que funciona como antígeno de superfície, favorecendo a aderência de outras bactérias (Andrea \& Cynthia, 2014).

As bactérias são constituídas por uma membrana que contém um complexo de proteínas, lipídios e pequenas quantidades de carboidratos, fazendo sua proteção como um empecilho osmótica para célula e fornece uma âncora para as enzimas celulares biosintética e respiratória (Lima, Borges, Parente, Victória \& Oliveira 2015).

Staphylococcus aureus é uma bactéria comensal comum em humanos, temporariamente e continuamente colonizando as narinas, de cerca de $20 \%$ dos indivíduos. É um patógeno oportunista que pode causar efeitos de superfície e infecções invasivas e potencialmente fatais (Foster \& Geoghegan, 2015).

Staphylococcus aureus são bactérias que se organizar em forma de cachos e são apresentados em coloração roxa pela coloração de Gram-positiva "parecidos com cachos uvas", esses organismos podem crescer em até 10\% NaCl, o nome aureus significa dourado ou amarelo, que caracteriza colônias que são tipicamente amarelas pigmentado, liso, todo saliente e hemolítico (Taylor \& Unakal, 2020).

O organismo humano secreta secreções e fatores localizados na superfície que promovem a colonização e infecção, na superfície da pele os organismos se aderem com facilidades as proteínas que permitem aderir as células e tecidos do hospedeiro, para invadir o epitélio e células endoteliais, para formar biofilme e para escapar do sistema imunológico de respostas (Foster \& Geoghegan, 2015).

\section{Fitoquímicos presentes no Allium sativum L.}

\section{Alcalóides}

Alcalóides formam um conjunto heterogêneo de compostos naturais, geralmente com estruturas complexas. São compostos de carbono, hidrogênio e nitrogênio e, na maioria dos casos, fazem parte de um anel heterocíclico, a maioria oxidado. Muitos autores tratam apenas os compostos contendo nitrogênio em heterocíclicos como alcalóides verdadeiros e os compostos contendo nitrogênio em cadeias laterais não cíclicas como proto-alcalóides. Sua fonte genética biológica geralmente 
vem de aminoácidos, mas vários alcalóides vêm de terpenos e esteróis. Apresentam atividade farmacológica ou toxicológica (Cabral \& Pita, 2015)

Os alcaloides são encontrados nos bulbos e folhas do Allium sativum L. Uma forma de notar a presença do alcaloide e a reação química da solução de iodo bismutado de potássio $\mathrm{K}$ (BiI4) com ácido diluído que formam precipitados laranja avermelhados em contato com os alcaloides ou compostos nitrogenados (Fonseca, Quefi, Alcócer, Pinto \& Carvalho, 2019). Os alcaloides apresentam carácter básico, contendo um ou mais átomos de nitrogênio e podem ter ação fisiológica no ser humano ou em outros animais. São utilizados nas aplicações terapêuticas para o tratamento de desordem lisossomal, infecções de doenças autoimunes com artrite e esclerose múltipla (Tomczak, \& Reichert, 2013).

\section{Terpenos}

Os terpenos são identificados como constituintes dos óleos voláteis, que apresentam diversas funções nas plantas, atraem polinizadores, proteção contra stress oxidativo, termo tolerância, proteção contra insetos, antifúngico, antibacteriano e herbívoros. Participa da origem dos hormônios de crescimento da planta vegetal, inibição do crescimento da raiz e germinação da semente (Tomczak, \& Reichert, 2013).

Os óleos essenciais que contem em sua composição terpenos mais complexos, bem como: citronelal e o cineol. Os terpenos conferem aos óleos essenciais propriedades antimicrobianas (Rivaroli, 2014).

\section{Saponinas}

As saponinas são subdivididas em duas classes, triterpênicas e esteroidais, ambas derivadas do precursor óxido de esqualeno, com 30 átomos de carbono. A altercação entre estas duas classes é que as saponinas esteroidais têm 3 grupos metila a menos com 27 átomos de carbono, enquanto as saponinas triterpênicas se mantêm com 30 átomos de carbono (Ribeiro, 2012)

As saponinas esteroidais podem ser avaliados os glicosídeos nitrogenados esteroidais, que são tratados como um grupo à parte alcalóides. A característica ácido pode ser devido à aparência de um grupamento carboxila na aglicona ou na cadeia de açúcares bem como: ácidos glicurônico e galacturônico, ou ambos. O caráter básico decorre da presença de nitrogênio, em geral sob forma de uma amina secundária ou terciária, como nos glicosídeos nitrogenados esteroidais (Teixeira, 2020).

\section{Compostos fenólicos}

Devido à importância dos compostos fenólicos e levando em consideração a quantidade significativa de lignina presente na casca do alho, o conteúdo de fenóis totais nos extratos da casca do alho que foi expresso em equivalentes de ácido gálico, que teve o maior teor de fenóis totais obtidos com (50/50 águas/Metanóis) 25,00 mg de fenóis \pm 1,52 g de casca do alho (Kallel et al., 2014).

Os taninos são substâncias fenólicas solúveis em água, é são capazes de formar complexos insolúveis em água com os alcaloides, e dá a característica de adstringência nos frutos e outros produtos plantas. Os complexos formados pelos taninos e proteínas e a base para suas propriedades inseticidas, fúngicas e bacterianas (Tomczak, \& Reichert, 2013).

Os vegetais que apresenta uma composição química rica em taninos, são aplicados na medicina tradicional para tratamentos de diarreias, antisséptico, anti-hemorrágico, problemas estomacais, anti-inflamatório, age sob ferimentos na derme impermeabilizando as camadas expostas (Tomczak, \& Reichert, 2013).

O potencial antibacteriano do extrato de Allium sativum L. pode estar relacionado aos taninos nele contidos, que são uma excelente substância antibacteriana, pois podem precipitar proteínas. Conforme a concentração do extrato diminui, a concentração de taninos e sua capacidade antibacteriana também diminuem (Caldas, Silva, Rodrigues, \& Silva, 2019). 
$\mathrm{Na}$ natureza, os flavonóides podem existir em diferentes formas estruturais. Quimicamente, a estrutura básica da maioria dos flavonóides é um esqueleto composto por 15 átomos de carbono. O esqueleto é composto por dois anéis de benzeno conectados por uma cadeia de três carbonos entre eles e o oxigênio como um heteroátomo. Eles também são considerados antioxidantes eficazes com uma ampla gama de funções bioquímicas, como íons metálicos quelantes e inibição da peroxidação lipídica (Santos \& Rodrigues, 2017; Botrel \& Oliveria, 2012).

Os flavonoides têm capacidades de proteção contra os efeitos maléficos dos raios ultravioletas nos tecidos vegetal. A atividade protetora dos flavonoides é devido a formação de complexos com proteínas solúveis que se ligam à parede celular bacteriana e alguns flavonoides lipofílicos podendo também causar ruptura da membrana plasmática de microrganismos (Teixeira, 2020).

Os resultados obtidos nos testes para teor total de flavonóides que contem nas cascas do alho, indicou que o extrato de (50/50 água/metanol), tem o maior teor de flavonóides ( $0,617 \mathrm{mg} / \mathrm{g}$ casas de alho seco), e o menor valor obtido foi 0,045 mg/g utilizado outras extrações (Kallel et al., 2014).

\section{Potencial antimicrobiano e fúngico do Allium sativum $\mathbf{L}$.}

O extrato envelhecido do alho obtido por extração hidroalcoólica, permite inativar isoenzimas e algumas enzimas como as peroxidases de aliinase. Assim, os seus principais compostos são basicamente S-alil-cisteina, Alil-mercaptano e saponinas (Cruz et al., 2016).

Os resultados que foram obtidos utilizando quatro tipos de óleos essências constatou que o óleo essências do alho foi suscetível a Staphylococcus aureus que criou halo de inibição (40 \pm 0), a Salmonella cholerasuis teve halo de inibição de (39.7 \pm 0.33 ), já o teste sobre a Escherichia coli não houver inibição (Santos, Carvalho, Barros \& Guimarães 2011).

Bactérias Gram positivas e Gram negativas foram testadas com extratos solventes de casca de alho, sendo as bactérias Gram positivas que apresentaram inibição mínima, moderada, alta inibição e forte inibição, já as bactérias Gram negativas foram resistentes a exposição dos extratos, apresentação na Tabela 1 (Kallel et al., 2014).

Esses resultados parecem muito importantes considerando que S. aureus é uma cepa associada a doenças frequentemente infecção de ciscos pela produção de vários tipos de enterotoxinas que causar gastroenterite, que é um problema mundial em alimentos e Medicina Clínica (Kallel et al., 2014).

Além da contribuição dos compostos: organossulfuretos, fenólicos, saponinas entre outras substancias presente no Allium sativum L. e a alta atividade antioxidante dos extratos, esses compostos são responsáveis pelas as propriedades antimicrobianas (Kallel et al., 2014). 
Tabela 1. Atividade antibacteriana de extratos solventes de casca de alho contra bactérias Gram (+) e Gram (-).

\begin{tabular}{llllllll}
\hline EXTRATOS & \multicolumn{2}{c}{ MIC $(\mathrm{mg} / \mathrm{mL}$} & & & & \\
& Gram + & Gram + & Gram + & Gram- & Gram- & Gram- & Gram- \\
\cline { 2 - 7 } & B. subtilis & S.aureus & $\begin{array}{l}\text { B. } \\
\text { thuringiensis }\end{array}$ & P. aeruginosa & $\begin{array}{l}\text { K. } \\
\text { pneumoniae }\end{array}$ & E. coli & $\begin{array}{l}\text { S. } \\
\text { typhimurium }\end{array}$ \\
\cline { 2 - 7 } & $3(++)$ & $2(++)$ & $2(+++)$ & $10(+)$ & $10(-)$ & $10(-)$ & $10(-)$ \\
$\begin{array}{l}\text { Aquoso } \\
\text { Absoluto }\end{array}$ & $2(++++)$ & $2(+++)$ & $2(+++)$ & $10(+++)$ & $10(++)$ & $10(-)$ & $10(-)$ \\
$\begin{array}{l}\text { Etanol Absoluto } \\
\text { Metanol/Agua }\end{array}$ & $3(++)$ & $3(++)$ & $3(+)$ & $10(+)$ & $10(-)$ & $10(-)$ & $10(-)$ \\
$\begin{array}{l}50 / 50(\mathrm{v} / \mathrm{v}) \\
\text { Etanol/Agua } \\
850 / 50 \text { (v/v) }\end{array}$ & $3(++)$ & $2(++++)$ & $2(+++)$ & $10(+++)$ & $10(++)$ & $10(-)$ & $10(-)$ \\
\hline
\end{tabular}

Nota: Sem atividade antimicrobiana (-), zona de inibição $<1 \mathrm{~mm}$. Ligeira atividade antimicrobiana (+), zona de inibição $2-3$ mm. Atividade antimicrobiana moderada (++), zona de inibição $4-5 \mathrm{~mm}$. Alta atividade antimicrobiana (+++), zona de inibição 6-9 mm. Forte atividade antimicrobiana (++++), zona de inibição> $9 \mathrm{~mm}$. Desvio padrão $\pm 0,5 \mathrm{~mm}$ (Kallel et al., 2014).

Fonte: Kallel et al. (2014).

Nos resultados obtidos pelo método de difusão em disco, o Allium sativum L. apresentou potencial antimicrobiano para Escherichia coli. O resultado do óleo essencial do alho não obteve suscetibilidade, nas três concentrações de 25,50 e $100 \%$, não apresentaram eficácia. Já nos extratos do alho para as concentrações 25, 50 e $100 \%$, foi obtido resultados satisfatórios, onde o microrganismo testado foi sensível para os extratos. As concentrações de $25 \%$ formol halo de inibição de $6,22 \pm 4,27$, na concentração de $50 \%$ formol halo de inibição 9,22 $\pm 1,48$, já na concentração do extrato a $100 \%$ formol halo de inibição 13,33 $\pm 2,59$ ), à sensibilidade do microrganismo obteve eficácia notável. Os controles positivos utilizados tiveram halos de inibição com ciprofloxacina de 11,56 \pm 4,27 e levofloxacina halo de 13,44 \pm 3,43 respectivamente (Caldas, Silva, Rodrigues, \& Silva, 2019).

Tabela 2. Atividade antifúngica do Allium sativum L.

\begin{tabular}{|c|c|c|}
\hline AUTORES & METODOS & RESULTADOS \\
\hline $\begin{array}{l}\text { Fonseca, Passos, } \\
\text { Ninahuaman, Caroci \& Costa, } \\
2014\end{array}$ & Extrato de alho in natura & $\begin{array}{l}\mathrm{O} \text { alho in natura apresentou melhor efeito } \\
\text { inibitório frente às cepas de Cândida albicans. }\end{array}$ \\
\hline Li et al., 2016 & Óleo do alho & $\begin{array}{l}\text { O óleo de alho tem uma atividade antifúngica } \\
\text { mais forte contra Candida albicans. }\end{array}$ \\
\hline $\begin{array}{l}\text { Kumar, Kumar, Natarajan \& } \\
\text { Sreenivasan, } 2018\end{array}$ & Extrato de alho (pó do alho) & $\begin{array}{l}\text { Os extratos do alho pó foram capazes de induzir } \\
\text { um efeito antifúngico contra Candida albicans. }\end{array}$ \\
\hline $\begin{array}{l}\text { Caetano, Garcia, Gonçalves \& } \\
\text { Silva } 2021\end{array}$ & Prova do tubo germinativo & $\begin{array}{l}\text { Os resultados obtidos demonstraram que houve } \\
\text { atuação do alho sobre a amostra de Candida } \\
\text { albicans testada. }\end{array}$ \\
\hline
\end{tabular}

Fonte: Autores.

No estudo realizado por métodos de difusão de ágar utilizando discos de alho in natura $(0,18 \pm 0,01 \mathrm{~g})$, frente $a$ Candida albicans que apresentou um halo de inibição de 55,3 $\pm 2,6 \mathrm{~mm}(\mathrm{n}=12)$, enquanto o halo de inibição do controle positivo Miconazol (50 $\mu \mathrm{g}$ ) foi de $24 \pm 0,5 \mathrm{~mm}$ ( $\mathrm{n}=3$ ) (Fonseca, Passos, Ninahuaman, Caroci \& Costa, 2014).

Os resultados obtidos pela técnica de alimentos envenenados, mostra que a atividade ante fúngica CIM do óleo de Allium sativum L. versus cândida albicans foi de $0,35 \mu \mathrm{g} / \mathrm{mL}$, em comparação com outro microrganismo testado contra Penicillium funiculosum, o óleo do alho teve CIM de $0,69 \mu \mathrm{g} / \mathrm{mL}$ (Li et al., 2016). 
A curva cinética antifúngica do óleo de alho contra Candida albicans mostra que o óleo de alho tem um efeito antifúngico dependente do tempo e da dose. Devido à evaporação gradual e ao consumo de óleo de alho na cultura do caldo, um pequeno número de células persistentes de Candida albicans pode crescer após o período inicial de incubação, cuja duração está relacionada à concentração inicial de óleo de alho (Li et al., 2016).

No estudo feito utilizando Allium sativum L. confirmar que as concentrações liberadas dos agentes antifúngicos (extratos de plantas) dos materiais de revestimento macio foram capazes de induzir um efeito antifúngico contra Candida albicans na cultura de ágar (Kumar, Kumar, Natarajan \& Sreenivasan, 2018).

Candida albicans foi capaz de formar pseudo-hifas no tubo germinativo que foram mimetizados conforme nosso organismo em pouco tempo. Foi realizada a técnica com soro humano e incubada por no máximo 3 horas a $37^{\circ} \mathrm{C}$. E foi observado que não houve formação de tubo germinativo e nem pseudo-hifas quando adicionado ao soro 1 gota do extrato aquoso do alho, em controle negativo 1 gota da solução de nistatina também não houver formação. Em controle positivo foi utilizado apenas o soro, então as estruturas se formaram em apenas 2 horas (Caetano, Garcia, Gonçalves \& Silva 2021).

\section{Allium Sativum L. e a Candida albicans}

Candidíase é uma patologia oportunista acometidos por leveduras da espécie Candida, que apresenta diferentes manifestações clínicas, sendo capaz causar desde uma infecção centrada nas mucosas até uma doença alastrada potencialmente fatal, que pode acometer vários locais do corpo humano causados pelo crescimento excessivo da levedura, sendo a Candida albicans a gênero mais comum, estando presente em $60 \%$ dos isolados clínicos, além de outras espécies como C. parapsilosis, C. tropicalis, C. krusei. (Freire et al., 2016; Caetano, Garcia, Gonçalves \& Silva 2021).

Existem cerca de 200 espécies de Candida que habitam no trato gastrointestinal, sistema urinário, mucosas do trato respiratório e pele. Dentre elas, as mais predominantes são a Candida albicans, Candida, glabrata, Candida kruzei, Candida parapilosis e Candida tropicalis, que tem grande relevância clínica. Essas espécies originam a candidíase, e se aproveitam da situação, causando ao paciente infecções agudas crônicas que apresentam lesões sistêmicas ou superficiais. Isso se dá pela forma como a pessoa infectada irá tratar a infecção levando em consideração o tempo de infecção e a alternativa de tratamento (Oliveira, Cavalcante, \& Ribeiro, 2021).

Com o avanço da resistência aos antimicrobianos atuais, o estudo das plantas de uso medicinal tem sido aprofundado, como a finalidade de possibilitar alternativas mais eficaz na prevenção de doenças infecciosas em seres humanos, ao longo do tempo, muitas outras pesquisas foram realizadas expondo a eficiência e a veracidade das plantas de uso medicinal (Badke, Budó Silva \& Ressel, 2011; Fonseca, Passos, Ninahuaman, Caroci \& Costa, 2014).

É importante inserir remédios naturais alternativos para a candidíase porque, desta forma, o organismo dos pacientes geralmente imuno comprometidos não será muito afetado pelo tratamento com drogas sintéticas, pois diminui o ataque ao corpo. As terapias alternativas podem até fornecer prevenção porque podem ser inseridas na dieta do paciente ou aplicadas topicamente, reduzindo assim a chance de resistência microbiana. Portanto, o alho pode ser uma boa escolha para pacientes com candidíase cutânea-mucosa em tratamento (Caetano, Garcia, Gonçalves \& Silva 2021).

Foi testado que, ao usar um extrato de alho impregnado feito de bulbos, tem o maior efeito inibitório sobre Candida albicans em comparação com fatias aplicadas diretamente na placa de inoculação e nistatina usada com antifúngicos. Isso pode ter ocorrido porque os bulbos foram macerados durante o preparo dos extratos e a membrana externa do alho rompida, o que pode permitir que os princípios ativos sejam liberados após reação enzimática. Ajoene é um composto ativo com propriedades antifúngicas do alho, formado por uma mistura de alicina e enzimas, portanto, quando o alho é picado ou macerado, esses dois compostos se combinam para formar ajoene, o que explica o maior efeito do extrato antifúngico. (Burian, Sacramento \& Carlos, 2017). 
Neste estudo também mostraram uma maior atividade do extrato macerado quando comparado a outras formulações. Os testes feitos utilizando extrato fresco de alho in natura Allium sativum L., após a realização dos testes de difusão em Ágar técnica do disco e do Poço, apresentaram halos de inibição mm, formados ao redor dos discos impregnados com $20 \mu \mathrm{L}$ e dos poços, nos quais foram depositados $100 \mu \mathrm{L}$ do extrato fresco de Allium sativum L. A medida do diâmetro do halo de inibição

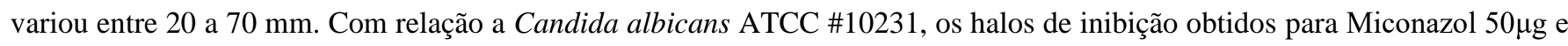
Extrato fresco de alho $20 \mathrm{~mL}$ e $100 \mathrm{~mL}$ foram respectivamente $60,0 \pm 0,03 ; 60,0 \pm 0,0$ e 70,0 \pm 0,0 (Milani, Teixeira, Sousa, Abreu \& Ninahuaman, 2016).

O extrato hidroalcóolico de alho Allium sativum L. formulado em matriz de base gel apresenta atividade antifúngica contra Candida albicans ATCC90038, in vitro. Os formulados que apresentaram melhores resultados foram T5 e T6. Considerando as proporções dos formulados testados, observasse que as duas maiores proporções do formulado T5: 20\% e T6: $40 \%$ formaram um grupo com padrão de similaridade com o tratamento controle T7 controle negativo com fluconazol (Souza, 2019).

\section{Allium Sativum L. e o Staphylococcus Aureus}

O Staphylococcus aureus é o patógeno de várias infecções humanas e é a infecção bacteriana mais comum em humanos, esse microrganismo, mesmo estando presente na microbiota normal do corpo humano, tem sido considerado um dos principais agentes de infecções em ambientes hospitalares, sendo na maioria das vezes superficiais. Por esse fato, é um microrganismo que possuem grandes índices de toxinfecções (Taylor \& Unakal, 2020).

Portanto, é um microrganismo com alto índice de infecção tóxica, sendo causa de elevada morbidade em hospitais, principalmente em unidades de terapia intensiva. Embora sejam sensíveis a soluções antissépticas e outros produtos, esses microrganismos podem sobreviver em ambientes secos por muito tempo, o que é benéfico para que se multipliquem nesses ambientes e, assim, infectem os pacientes. A disseminação desse tipo de bactéria é causada pelas precárias condições sanitárias dos hospitais tendo como fonte de transporte e contaminação exógena as próprias mãos dos profissionais de saúde, o que os obriga a ter um cuidado maior, lavando as mãos com frequências para evitar tais infecções (Lima, Borges, Parente, Victória \& Oliveira 2015).

Entre esses parâmetros, existe um difícil desafio para o combate de infecções hospitalares pelos serviços de saúde. Há algum tempo, há importância de associações de tratamento para esses casos, já vem sendo levantada em estudos durante um tempo, visando novos meios de tratamentos com maior eficácia de forma mais segura, sendo o menos tóxico possível, assim tendo a importante de inserir meios de tratamentos naturais alternativos principalmente quando se trata da Staphylococcus áureos, bactéria gram positiva com grande capacidade de patogenia e alta virulência (Almeida, Godoi, Santos, Lima \& Oliveira, 2013; Caetano, Garcia, Gonçalves \& Silva 2021).

De acordo com a literatura, esse efeito antibacteriano do Allium Sativum L. pode ser atribuído às suas múltiplas composições fitoquímicas, na maioria dos casos tem a ver com o processo de inibir a síntese de proteínas bacterianas, que por sua vez afeta está diretamente relacionado à patogenicidade (Almeida, Godoi, Santos, Lima \& Oliveira, 2013).

As propriedades químicas do Allium Sativum L. tem uma resposta ativa sobre os microrganismos Staphylococcus Aureus, atuando de forma que podem inibir o crescimento do microrganismo ou retarda o crescimento, dessa forma parando o crescimento da sua replicação (CRUZ, 2015).

$\mathrm{Na}$ análise bioquímica do extrato aquoso do alho, foi comprovado que os componentes da fonte de enxofre como aliina, alicina e o ajoeno, têm um impacto significativo no metabolismo dos microrganismos, têm efeitos antibacterianos contra o microrganismo Staphylococcus aureus (Almeida, Godoi, Santos, Lima \& Oliveira, 2013; Fonseca, Passos, Ninahuaman, Caroci \& Costa, 2014). 


\section{Considerações Finais}

Diante disso, a pesquisa teve como objetivo mostrar os principais metabólitos provenientes do Allium sativum L. e verificar sua resposta frente à leveduras e bactérias Gram positivas e Gram negativas. O objetivo foi atendido de forma eficiente, porque efetivamente o trabalho pôde mostrar que houve remissão nas colônias dos microrganismos de acordo com o melhor método de extração utilizado, além de definir qual o melhor extrato para cada microrganismo, uma vez que ambos possuem metabolismos e estruturas distintas. A utilização do alho in natura, extratos aquosos a partir do pó do olho e do alho fresco, assim como o extrato oleoso, foram os alvos para os resultados de inibição de crescimento. O Allium sativum L. teve um efeito antifúngico em várias pesquisas realizadas, inibindo o crescimento e filamentação de Cândida albicans. O extrato macerado mostrou uma maior atividade, tendo ação antifúngica sobre a levedura. Nos estudos citados sobre a ação do alho no combate as bactérias, mostra inibição com vários métodos de extração, cada extração teve sua peculiaridade assim formando inibição sobre elas. As bactérias Gram positivas foram as mais sensíveis sob a ação do Allium sativum L. já as Gram negativas tiveram pouca sensibilidade ou nenhuma sensibilidade com a presença do Allium sativum L. visto que as estruturas das membranas mudam.

Visto que os trabalhos citados monstrão uma realidade que se torna possível com testes utilizando Allium sativum L. em potencial antimicrobiano, ficando aberto a novo estudos a extração dos ativos presente, bem com isolar estes para testes com estudos clínicos, assim quantificando doses precisas para tratamento com menores efeitos secundários.

\section{Referências}

Almeida, G. D., Godoi, E. P., Santos, E. C., Lima, L. R. P. D., \& Oliveira, M. E. D. (2013). Extrato aquoso de Allium sativum potencializa a ação dos antibióticos vancomicina, gentamicina e tetraciclina frente Staphylococcus aureus. Revista de Ciências Farmacêuticas Básica e Aplicada, 34(4), 487-492. https://locus.ufv.br//handle/123456789/16966

Andrea, M. P. M., \& Cynthia, G. V. (2014). Bacterias gram negativas. Revista de Actualización Clínica, 49, $2609-2613$. http://www.revistasbolivianas.org.bo/pdf/raci/v49/v49_a05.pdf

Badke, M. R., Budó, M. D. L. D., Silva, F. M. D., \& Ressel, L. B. (2011). Plantas medicinais: o saber sustentado na prática do cotidiano popular. Escola Anna Nery, 15(1), 132-139. https://doi.org/10.1590/S1414-81452011000100019

Basso, M. E., Pulcinelli, R. S. R., Aquino, A. R. C., \& Santos, K. F. (2016). Prevalência de infecções bacterianas em pacientes internados em uma unidade de terapia intensiva (UTI). RBAC, 48(4), 383-8. https:/doi.10.21877/2448-3877.201600307

Botrel, N., \& Oliveira, V. R. (2012). Cultivares de cebola e alho para processamento. In Embrapa Hortaliças-Artigo em anais de congresso (ALICE). Horticultura Brasileira, Brasília, DF, 30(2), 8420-8434. https://www.alice.cnptia.embrapa.br/bitstream/doc/940923/1/PAL41CBO522012.pdf

BRASIL. Agência Nacional de Vigilância Sanitária. Resolução Da Diretoria Colegiada - RDC N²6, De 13 De Maio De 2014 . Pág. 1, Art. $2^{\circ}$, § $1^{\circ}$. Disponível em: https://bvsms.saude.gov.br/bvs/saudelegis/anvisa/2014/rdc0026_13_05_2014.pdf

Burian, J. P. (2016). Efeito imunomodulatório e controle da infecção fúngica do extrato de alho (Allium sativum L.) em modelo murino de esporotricose. repositório institucional UNESP, Araraquara. http://hdl.handle.net/11449/138189.

Cabral, C., \& Pita, R, J. (2015). "Alcalóides - Relevância na Farmácia e no Medicamento. Centro de estudos interdisciplinares do século XX - Grupo de história e sociologia da ciência e da tecnologia Ciclo de exposições. https://www.uc.pt/ffuc/patrimonio_historico_farmace utico/exposicoes/exposicoestemporarias/1exposicao.pdf

Caetano, G. M., Garcia, G. A., Gonçalves, T. B., \& da Silva, J. L. M. (2021). Atividade Antifúngica Do Alho (Allium Sativum) Sobre Candida Albincans/Antifungal Activity Of Garlic (Allium Sativum) About Candida Albicans. Revista Brasileira Multidisciplinar (ReBram), 24(1), 112-127. https://revistarebram.com/index.php/revistauniara

Caldas, F. F, Silva Filho, J. P, Rodrigues, C. A. R, \& da Silva, D. P (2019). Atividade antimicrobiana do alho (Allium sativum L.) frente a bactéria causadora de infecção do trato urinário. Journal of Biotechnology and Biodiversity, 7(1), 217-224. DOI: https://doi.org/10.20873/jbb.uft.cemaf.v7n1.caldas

Cruz, A. C. R. D. (2015). Potencial terapêutico do alho. Instituto Superior De Ciências Da Saúde Egas Moniz. http://hdl.handle.net/10400.26/11322

Cruz, A. J., Brito, I. P., Sobral, M. A., Sousa, A. T., Alves, E. F., Andreza, R. D. S., \& Aquino, P. E. (2016). Avaliação da atividade antibacteriana e moduladora dos extratos metanólico e hexânico da folha de Allium cepa. Ciencias de la salud, 14(2), 191-200. doi.org/10.12804/revsalud14.02.2016.04

Cunha, A. L., Moura, K. S., Barbosa, J. C., \& dos Santos, A. F. (2016). Os metabólitos secundários e sua importância para o organismo. Diversitas Journal, 1(2), 175-181. https://doi.org/10.17648/diversitas-journal-v1i2.332 
Felix, A. L., Medeiros, I. L., \& de Medeiros, F. D. (2018). Allium Sativum: uma nova abordagem frente a resistência microbiana-uma revisão. Brazilian Journal of Health Review, 1(1), 201-207. https://www.brazilianjournals.com/index.php/BJHR/article/view/662/562

Figueredo, C. A. D., Gurgel, I. G. D., \& Gurgel Junior, G. D. (2014). A Política Nacional de Plantas Medicinais e Fitoterápicos: construção, perspectivas e desafios. Physis: Revista de Saúde Coletiva, 24, 381-400. https://doi.org/10.1590/S0103-73312014000200004

Fonseca, A., Quefi, B., Alcócer, J. C., Pinto, O. \& Carvalho, R. M. (2019). Análise fitoquímica e atividades biológicas do alho. Enciclopédia Biosfera, 16(29), 156. DOI: 10.18677/EnciBio_2019A10

Fonseca, G. M., Passos, T. C., Ninahuaman, M. F. M. L., Caroci, A. S., \& Costa, L. S. (2014). Avaliação da atividade antimicrobiana do alho (Allium sativum Liliaceae) e de seu extrato aquoso. Revista brasileira de plantas medicinais, 16, 679-684. https://doi.org/10.1590/1983-084X/12_150

Foster, T. J., \& Geoghegan, J. A. (2015). Chapter 37-Staphylococcus aureus. Molecular Medical Microbiology, 2nd ed.; Tang, Y.-W., Sussman, M., Liu, D., Poxton, I., Schwartzman, J., Eds, 655-674. Academic Press: Boston, NY, USA, p. 655-674. https://doi.org/10.1016/B978-0-12-397169-2.00037-8

Freire, J. C. P., Nóbrega, M. T. C., de Oliveira-Júnior, J. K., Freire, S. C. P., Ribeiro, E. D., \& de Oliveira Lima, E. (2016). Atividade antifúngica de fitoterápicos sobre espécies de Candida: uma revisão de literatura. Archives Of Health Investigation, 5(6). 307-310 http://dx.doi.org/10.21270/archi.v5i6.1790Arch

Goés, A. C. C., da Silva, L. S. L., \& de Castro, N. J. C. (2019). Uso de plantas medicinais e fitoterápicos: saberes e atos na Atenção Primária à Saúde. Revista de Atenção à Saúde. 17(59) 2359-4330. https://doi.org/10.13037/ras.vol17n59.5785

Kallel, F., Driss, D., Chaari, F., Belghith, L., Bouaziz, F., Ghorbel, R., \& Chaabouni, S. E. (2014). Garlic (Allium sativum L.) husk waste as a potential source of phenolic compounds: Influence of extracting solvents on its antimicrobial and antioxidant properties. Industrial Crops and Products, 62, 34-41. https://doi.org/10.1016/j.indcrop.2014.07.047

Kifayatullah, M., Senguptha, P., Mustafa, M. S., Das, S. K., \& Sisugoswomi, M. (2015). Evaluation of ethanolic extract of Pericampylus glaucus (Lamk.) Merr for total phenolic, total flavonoids contents and in-vitro anti-oxidant activity. International Journal of Pharmacognosy and Phytochemical Research, 7 , $677-683$.

Kumar, S. M., Kumar, V. A., Natarajan, P., \& Sreenivasan, G. (2018). Antifungal efficacy and the mechanical properties of soft liners against Candida albicans after the incorporation of garlic and neem: An in vitro study. Journal of International Society of Preventive \& Community Dentistry, 8(3), 212. DOI: 10.4103 / jispcd.JISPCD_343_17

Lawal, B., Shittu, O. K., Oibiokpa, F. I., Mohammed, H., Umar, S. I., \& Haruna, G. M. (2016). Antimicrobial evaluation, acute and sub-acute toxicity studies of Allium sativum. Journal of Acute Disease, 5(4), 296-301. https://doi.org/10.1016/j.joad.2016.05.002

Li, W. R., Shi, Q. S., Dai, H. Q., Liang, Q., Xie, X. B., Huang, X. M., ... \& Zhang, L. X. (2016). Antifungal activity, kinetics and molecular mechanism of action of garlic oil against Candida albicans. Scientific Reports, 6(1), 1-9. http://dx.doi.org/10.1038/srep22805

Lima, M. F. P., Borges, M. A., Parente, R. S., Victoria, R. C. V., \& De Oliveira, M. E. (2015). Staphylococcus aureus e as infecções hospitalares-Revisão de Literatura. Revista Uningá Review, 21(1). http://34.233.57.254/index.php/uningareviews/article/view/1616/1227

Lima, A. A., Alexandre, U. C., \& Santos, J. S. (2021). O uso da maconha (Cannabis sativa L.) na indústria farmacêutica: uma revisão. Research, Society and Development, 10(12), e46101219829-e46101219829 http://dx.doi.org/10.33448/rsd-v10i12.19829

Lozano, A. F. Q., Bagne, L., \& Hora, D. (2015). Uma abordagem dos efeitos terapêuticos do Allium sativum (alho) no sistema imunológico. Revista Científica da FHO| UNIARARAS v, 3(1). http://www.uniararas.br/revistacientifica/_documentos/art.9-3-1.pdf

Menezes, J. M. R., Porto, M. L. S., \& Pimenta, C. L. R. (2016). Perfil da infecção bacteriana em ambiente hospitalar. Revista de Ciências Médicas e Biológicas, 15(2), 204-207. https://periodicos.ufba.br/index.php/cmbio/article/download/15027/12746

Milani, H. L., Teixeira, A. X. V., de Sousa, E. C., de Abreu, V. A., \& Ninahuaman, M. F. M. L. (2016). Avaliação da atividade antimicrobiana in vitro do alho (Allium sativum) in natura. Acta Scientiae Biological Research, 1(1), 47-58. https://www.revistas.unasp.edu.br/acb/article/view/732

Oliveira, E. B., da Silva Cavalcante, L. B., \& Ribeiro, D. L. R. (2021). Atividade antimicrobiana do Allium Sativum em combate a Cândida Albicans e Staphylococcus Aureus: uma revisão de literatura. Brazilian Journal of Development, 7(1), 9205-9231. http://dx.doi.org/10.34117/bjdv7n1-623

Pigatto, G., Lovison, O. V. A., \& Cattani, F. (2019). Prevalência de infecções fúngicas em um laboratório de análises clínicas da cidade de Veranópolis, Rio Grande do Sul. Revista Brasileira Análises Clínica. 51(3): 202-207. http://dx.doi.org/10.21877/2448-3877.201900794

Ribeiro, B. D. (2012). Estratégias de Processamento Verde de Saponinas da Biodiversidade Brasileira. Escola de Química, Universidade Federal do Rio de Janeiro, 187. http://tpqb.eq.ufrj.br/download/processamento-verde-de-saponinas.pdf

Rivaroli, D. C. (2014). Níveis de óleos essenciais na dieta de bovinos de corte terminados em confinamento: desempenho, características da carcaça e qualidade da carne. Repositório institucional, UNESP. Botucatu. http://hdl.handle.net/11449/95277

Santana, D. P., Ribeiro, E. L., Menezes, A. C. S., \& Naves, P. L. F. (2013). Novas abordagens sobre os fatores de virulência de Candida albicans. Revista de Ciências Médicas e Biológicas, 12(2), 229-233. http://repositorio.ufba.br/ri/handle/ri/23079

Santos, D. S., \& Rodrigues, M. M. F. (2017). Atividades farmacológicas dos flavonoides: um estudo de revisão. Estação Científica (UNIFAP), 7(3), 29-35. ttp://dx.doi.org/10.18468/estcien.2017v7n3.p29-35

Santos, J. C., Carvalho Filho, C. D., Barros, T. F., \& Guimarães, A. G. (2011). Atividade antimicrobiana in vitro dos óleos essenciais de orégano, alho, cravo e limão sobre bactérias patogênicas isoladas de vôngole. Semina: Ciências Agrárias, 32(4), 1557-1564. http://dx.doi.org/10.5433/1679-0359.2011v32n4p1557 
Research, Society and Development, v. 10, n. 14, e108101421699, 2021

(CC BY 4.0) | ISSN 2525-3409 | DOI: http://dx.doi.org/10.33448/rsd-v10i14.21699

Silva, P. L., Silva, E. M., do Carmo, M. D. G. T., \& de Souza Cardoso, F. (2016). Fitoterapia, Allium sativum e hipercolesterolemia: uma revisão. Revista de Atenção à Saúde, 14(49), 78-83. https://doi.org/10.13037/ras.vol14n49.3746

Souza, L. C. D. (2019). Atividade antifúngica de extrato Hidroalcóolico de alho em matriz de gel contra Candida albicans. Repositório Institucional, Mangabeira. http://dx.doi.org/131.0.244.66:8082/jspui/handle/123456789/1924.

Taylor T. A, Unakal C. G. (2017). Staphylococcus Aureus. Livro da In: StatPearls. StatPearls Publishing, Treasure Island (FL). https://europepmc.org/article/nbk/nbk441868

Teixeira, C. C. L. (2020). A Fitoterapia Como Alternativa Terapêutica: O Alho Bravo (Mansoa Sp) E Seus Constituintes Químicos. Repositório Instrucional da UFPI. Teresina. https://repositorio.ufpi.br/xmlui/bitstream/handle/123456789/2299/DISSERTA\%c3\%87\%c3\%83O\%20\%20FINA L\%20CAPA\%20 DURAO K.pdf?sequence=1

Tomczak, M., \& Reichert, S. Estudos Fitoquímicos Adicionais com as folhas E. Itajai. https://www.greenmebrasil.com/wp-content/uploads/2016/10/MarceloTomczak-Simone-Reichert.pdf

Veríssimo, C., Sabino, R., Martins, C., \& Brandão, J. (2016). Infecção fúngica em Portugal-o gigante adormecido. Infeção e Sepsis, 2, 19-27. 